\title{
De Alima a Xilim: a memória ancestral e o colonialismo no romance Portagem, de Orlando Mendes
}

\author{
Clauber Ribeiro Cruz ${ }^{1}$
}

RESUMO: este trabalho analisa os traços da ancestralidade no espaço da memória a partir da resistência em meio à situação colonial vivenciada por Moçambicanos nas décadas de 60 e 70 do século XX. Para isso, o romance Portagem (1966), do escritor moçambicano Orlando Mendes (1916-1990), mostrará como a ancestralidade, junto ao espaço colonial, se posiciona dentro do processo de formação da literatura e da sociedade moçambicana.

ABSTRACT: this paper analyses the ancestral setting of memoir and its resistance in the colonial situation lived by Mozambique in the $60^{\prime}$ s and $70^{\prime}$ s of the $20^{\text {th }}$ century. Thus, the novel Portagem(1966), written by the Mozambican writer Orlando Mendes (1916-1990), is going to present how the ancestry, combined with the colonial setting, is going to behave itself on a process of the Mozambican literature formation and its society.

PALAVRAS-CHAVE: Memória; Espaço ancestral; Exílio; Literatura Moçambicana; Portagem. KEYWORDS: Memoir; Ancestral setting; Exile; Mozambican literature; Portagem.

Escrito na década de 50, mas só publicado em 1966, o romance Portagem, do escritor moçambicano Orlando Mendes(1916-1990), segundo o próprio autor, é um "velho romance de um tempo que nem calado se podia pensar em nossa vida" (MENDES, 1966, p.2). O espaço de tempo entre a criação da obra e a sua publicação, por volta de 16 anos, acontece devido à colonização portuguesa em Moçambique que submeteu a população nativa ao árduo trabalho escravo, deixando-a sem voz ativa diante das escolhas do colonizador. Assim, conforme cita Orlando Mendes, a época do colonialismo em Moçambique tanto repreendia a população quanto às publicações dos velhos romances, pois pensar sobre a vida e escrever sobre ela, certamente,

${ }^{1}$ Clauber CRUZ, Mestrando(UNESP-FCL/Assis)

E-mail: clauber.ribeiro@hotmail.com 
causariam graves consequências. Portanto, o silêncio reinava da mesma forma que o regime imperial.

Havia uma forte censura nos jornais, principalmente para produções de textos, obras e notícias relacionadas à temática do colonialismo. Sem falar, que as publicações em Moçambique eram muito precárias, tendo casos de autores que publicavam primeiro fora de seu país para, posteriormente, terem seus livros divulgados nos domínios de sua terra natal. Mas com o surgimento da FRELIMO (Frente de Libertação de Moçambique) no início dos anos 60, um respaldo maior foi dado e assegurado aos escritores, os quais, muitos deles, também faziam parte da Frente de Libertação do país.

Com isso, uma maior liberdade é instaurada, aos poucos, no território e, consequentemente, com a diminuição da censura, os textos vêm à tona, quebrando o silêncio de um tempo no qual era proibida a propagação de ideias, pois o desenvolvimento intelectual resultaria no questionamento do sistema colonial pelos nativos, tudo que Portugal não queria.

Esse romance privilegia uma literatura vinculada à tentativa da criação de um espaço literário nacional em Moçambique, pois ele é escrito dentro de um panorama anticolonial, em que a literatura é um instrumento cívico, de conscientização. Portagem contribui para o fortalecimento da sistematização da literatura moçambicana em espaço de formação, pois a obra representa um momento muito importante para o desenvolvimento literário e social em Moçambique, uma vez que os textos, contextos e temas estão, paulatinamente, envolvidos, engajados e estimulados pela temática central do período: o anticolonialismo.

As personagens do romance estão envolvidas num emaranhado movimento de choques entre as contradições decorrentes da nítida discriminação racial em Moçambique da época. Deste modo, Orlando Mendes submerge numa atmosfera do comportamento humano, e para o autor: "os negros, os mulatos, os indianos - os chamados monhés - e mesmo uma 
parte dos colonos brancos, todos eram vítimas, em grau variável, de um mesmo processo: o colonialismo." (MENDES, p.2).

Por isso, Portagem é considerado o primeiro romance de literatura moçambicana que reflete a inaptidão do mestiço na sociedade colonial de Moçambique, prensado entre brancos e negros, junto à dor que esta cor carregará num país cercado de preconceitos raciais e injustiças sociais instauradas no período colonial.

Assim sendo, em meio a uma situação em que as vozes são sufocadas ao silêncio, sem poderem ressoar seus desejos e ambições, a luta pela mudança da realidade fica presa a uma vontade inaudível. Por sua vez, uma das possíveis maneiras para alteração da situação presente é deixar ecoar as vozes do passado sobre ele, isto é, o apelo à memória e ao resgate da preservação da ancestralidade, deve ocupar um local de destaque na formação e na resistência de uma nação perante o invasor estrangeiro.

A narrativa, como se fosse a própria nação, (narrada e articulada por suas personagens marginalizadas pelo processo imperialista-colonialista) dá vida e existência a sua história: "Ouvir o apelo do passado significa também estar atento a esse apelo de felicidade e, portanto, de transformação do presente, mesmo quando ele parece estar sufocado e ressoar de maneira quase inaudível" (GAGNEBIN, 2006, p.12).

A preservação da memória, deixada, na sua grande maioria, pelas vozes dos ancestrais aos seus descendentes e, também, as escritas e documentos produzidos pelos intelectuais, são instrumentos essenciais na constituição e rememoração de uma sociedade, pois ao trazer o passado ao presente, uma nova perspectiva é acrescida a ele.

A figura do ancestral é muito significativa dentro desse processo, pois é ela quem legitima e transfere aquilo que uma sociedade é na sua atualidade, isto é, as glórias de grandes feitos executados no passado darão mais condições essenciais à humanidade que reside no presente. Então, a preservação da memória junto à constituição de uma nação, segundo Ernest Renan, é formada pela legitimação dos sentimentos e sacrifícios daqueles que viveram no 
passado, em que os valores e tradições construídos ao longo de uma trajetória são transpassados e preservados para/pela a próxima geração.

A rememoração significa também uma atenção ao momento atual vivido, ou melhor, uma importância aos ecos do passado sobre o presente, fazendo o uso da memória e da tradição fundadas num passado para serem utilizadas num momento transformador. Ernest Renan cita uma música espartana a fim de ilustrar a base de uma sociedade construída nos preceitos de seus antepassados refletidos em seu presente: "We are thatyouwere; wewillbethatyou are (Nós somos o que fomos; nós seremos o que você é) (tradução minha)" (BHABHA, 1990, p.19 apud RENAN, 1990, p.19). Esta canção fixa e reafirma a construção de uma nação como narração, somos o resultado daquilo que vocês foram transpassando as marcas deles para sermos o que somos. A narrativa, portanto, segue este ritmo e fluxo harmonioso, cantando seu passado e ressoando em nós na sua atemporalidade.

A narração do espaço ancestral traz junto a ela, por conseguinte, a voz de sua pátria, em especial e, mais destacadamente, para aquelas que estão num processo de construção, sendo ele colonial ou não, ou seja, ao narrar-se sobre o passado, a nação engendra-se no seu conteúdo, já que nações são como narrativas e, no caso de Portagem, nação e narração cruzam-se a todo o momento, pois a sensação de uma terra em transformação dominada por estrangeiros são refletidas em suas personagens. No livro Nationand Narration, de HomiBhabha, esta questão é trabalhada, sendo que uma das afirmações é que a rememoração, por meio das narrativas, reflete seu espaço de criação, por isso se tem a nação como narração, expressando a sua pluralidade de vozes. E para firmar e dar mais sustentação a esta ideia, basta pensar numa das concepções do gênero romanesco, o qual expressa a voz plural de suas personagens em sua narrativa, (suas indagações, desilusões, alegrias etc.) assim como uma nação cuja pluralidade de vozes a envolve, representando seu povo, mantendo viva as suas vidas, imagens, enfim, sua memória preservada. Segundo Jeanne Marie Gagnebin, no seu livro Lembrar, Escrever, Esquecer, tem-se o seguinte: 
na história, na educação, na filosofia, na psicologia o cuidado com a memória fez dela não só um objeto de estudo, mas também uma tarefa ética: nosso dever consistiria em preservar a memória, em salvar o desaparecido, o passado, em resgatar, como de diz, tradições, vidas, falas e imagens. (GAGNEBIN, p.87)

Contudo, mais importante do que mantê-la viva, deve-se resgatar a memória com o propósito de abri-la para o futuro, isto é, ela deve agir como um instrumento reflexivo sobre o presente, principalmente, na terra colonizada, em que a ancestralidade vive como forma de resistência ao espaço oprimido pelo colonizador. É necessário olhar para o passado como constituinte do presente, o qual será lembrado, refletido (reescrito) e esquecido (para que posteriormente possa ser relembrado novamente).

Deste modo, os escritores que vivenciaram este espaço colonial vergonhoso, descobrem que a sua dignidade está viva no passado, então, levam para os seus textos uma temática voltada à ancestralidade, ao espaço da memória, acrescido do fio de esperança apontando para o futuro: eis a sua glória e sua solenidade:

Inconscientemente talvez os intelectuais colonizados, não podendo enamorar-se da história atual de seu povo oprimido, não podendo admirar sua presente barbárie, deliberam ir mais longe, mais fundo, e foi com alegria excepcional que descobriram que o passado não era de vergonha mas de dignidade, de glória e de solenidade...

(FANON, 1961, p.175)

O romance Portagem é uma obra que retrata um panorama racial e protestatório moçambicano envolvido pelos conflitos sociais do período colonial, tendo como protagonista a personagem João Xilim, o mulato Xilim, a qual carrega em sua cor toda sua dor: a nova raça mal infamada. Portanto, a obra foca uma sociedade na qual o mulato João Xilim transita, cercado pelos efeitos que a situação social irá transferir a sua vida por meio de suas relações sociais.

No primeiro capítulo do romance é possível evidenciar que as ações ocorrem no plano do ancestral, isto é, a personagem sobre a qual o narrador 
descreve representa a memória e os traços ancestrais, a Velha Alima, a personagem que carregará o destino da narrativa e, por sua vez, o destino da sua nação (nação como narração). O tempo da narrativa sucede no presente, mas é transpassado pelo passado, há a tentativa do resgate do passado como forma de abertura para um presente de esperança. Quem faz essa ponte entre passado-presente é Alima, suas ações estão centradas num presente solitário e desiludido, mas constituído e mantido por sua memória deixada como herança. É a única representante da família Mafanissane cuja importância deposita-se sobre a terra na qual permanece, sua função e missão é dispersar e manter viva essa história, essa memória que conta sua origem e a de seus descendentes.

O ritmo do discurso da Velha Alima segue um andamento lento e nostálgico durante o primeiro capítulo, sempre mostrando um retorno ao que não volta mais, isto é, ao passado, ao apego a terra, à família, enfim, às tradições sobre uma planície miserável, contudo, é ali que se sente digna. A narração, assim com a ação, segue em ritmo lento, acompanhada de abandono e solidão.

Em sua palhota, sozinha, somente com a luz do sol como companhia, a velha não consegue nem mais sorrir, as rugas provocadas pelo aparente sorriso misturam-se entre alegrias, tristezas, desilusões em sua velhice erma. Como não há ninguém mais a vista de sua terra, tudo vai se esquecendo, sua história, sua memória. Nunca deixou sua palhota, a não ser na época da grande seca, por isso, tudo que conhece do mundo externo são os ramos das árvores fincadas no horizonte de sua planície. Melhor mesmo não ter conhecido a transformação em seu vilarejo, pois se envergonharia em ver as modificações causadas pelo colonizador em seus descendentes:

A velha sai da palhota e fecha os olhos doridos pela luz crua do sol. Depois abre-os lentamente e a boca encarquilha-se-lhe num sorriso aparentemente sem sentido. No terreiro não há ninguém que lhe faça lembrar das coisas do mundo que está esquecendo. Tudo quanto ela entende do mundo exterior é aquele ranger medroso dos ramos nus da árvore mirrada, sacudidos pelo vento quente e vagaroso que passa e se esconde na terra.

(MENDES, p.5) 
Em meio ao espaço da solidão, já com seus olhos cansados e doloridos perante aquilo que vê em sua frente, a Velha Alima vive um destino sem sentido, sem ambição, pois tudo aquilo que foi feito para que estivesse ali, as lutas em prol do país, os movimentos de libertação da terra e de escravos, não estão mais presentes, tudo está se esquecendo e, vagarosamente, o vento quente vai levando essa memória pela terra, cuja vergonha se esconde nela mesma, nem mesmo a terra tem mais orgulho em mostrá-la.

Na família tradicional africana o orgulho e a reverência pelo passado e antepassado é uma forma de manter viva as tradições e a fidelidade para com suas crenças, por isso, a guardiã da aldeia, Alima, permanece sozinha na terra do ancestral, simbolizando a resistência, perpetuando os antepassados, tentando ligá-los a nova geração.

Na tentativa de salvar seu povo, Alima permanece sobre a sua planície e resiste até seu último minuto de vida, mas o espaço no qual vive é áspero, seco, miserável, sua dor fica presa sob este vilarejo, então, parece que sua luta solitária fica suscetível ao apagamento, pois uma única voz em meio a uma multidão contra é enfraquecida, sua sustentação é debilitada, mas, mesmo assim, seu embate não é esmorecido, seu desejo de ficar resiste a tudo que a rodeia.

A personagem velha Alima representa o desejo de uma nação liberta dos colonizadores portugueses, isto é, é a única que aceita lutar contra a invasão do branco português não se corrompendo aos valores e costumes europeus, fica em sua palhota, na solidão de seu desejo. Mas tudo isso teve um custo, este isolamento e esta luta erma resultam na não repercussão de sua voz e de sua solidão, com isso, espraia-se o seu desejo não realizado, pelo menos enquanto estava viva. Teria sido uma luta em vão? João Xilim, seu neto, terá algum envolvimento nesta questão? Vejamos, Mia Couto, numa intervenção da premiação dos 12 melhores romances africanos, em Cape Town, em julho de 2002, fala sobre qual África o escritor africano escreve, levantando uma questão muito pertinente: a visão do escritor africano e do leitor sobre a mestiçagem. Mia couto diz que quando se fala sobre mestiçagem, o híbrido, há normalmente 
uma conotação negativa posta sobre o termo, ou seja, como se nunca houvesse tido uma troca mútua, mesmo que indireta, neste processo entre colonos e colonizadores, somente deste para aquele. Mia Couto diz: "E se nos mestiçamos significa que alguém mais, do outro lado, recebeu algo que era nosso..." (COUTO, 2002, p.1) Isto é, assim como os colonizadores contaminaram com seus "costumes de civilidade" a cultura local africana, automaticamente, os europeus também receberam algo do ser africano. O que Mia Couto possivelmente quer ressaltar é que mesmo que se busque a legitimação da ancestralidade, a sua tradição pura como marca genuína do ser africano, sendo o continente um resultante de diversidades mestiças, é quase impossível encontrar a marca de uma cultura ancestral homogênea.

Aliás, não existe pureza ao tratar-se da humanidade. Edward Said, no seu livro Cultura e Imperialismo, diz que todas as culturas estão envolvidas com as outras, nenhuma delas é homogênea, pura, e, devido ao advento do capitalismo, nenhuma cultura humana é isolada, mas sim extremamente heterogênea. A pluralidade da cultura está enraizada no outro, ou seja, a cultura são os outros, há uma forte hibridização dela, na qual as fronteiras simbolicamente foram rompidas e abertas à coletividade.

Então, voltando à questão sobre a luta da Velha Alima e conectando as duas ideias, há uma possibilidade deste fator, centralizada na personagem protagonista do romance, João Xilim, desenvolver-se. Ele já herda, em sua pele, as cores do híbrido (João Xilim é mulato, fruto do abraço mal infamado de uma negra com um branco), por isso, carrega em si o resultado do cruzamento das diversidades raciais e culturais que se cruzaram em Moçambique. Se Xilim irá ou não perpetuar a voz ancestral tão resistente em sua avó, isto ficará para o leitor refletir, mas algo já é possível adiantar, para que João Xilim consiga obter êxito sobre sua trajetória clandestina, certamente, ele terá que negar os conceitos do branco em sua morada, mas, ironicamente, fingir que os aceita, isto é, voltarse sobre seu passado e refleti-lo em seu presente. Eis uma arma poderosa: negar a ideia de ser europeu sendo um deles. Xilim vai viver nestes dois polos de sua 
terra, terá que aprender a conviver com a diversidade, equilibrando o que é, e aquilo que poderá ser.

Portanto, Alima, a Velha Alima, tem em suas mãos o destino dos ancestrais, mas essa ancestralidade corre o risco de ser levada junto ao esquecimento da própria terra, pois seus descendentes já não pensam desse jeito, ainda não conseguiram achar o equilíbrio entre seu passado e seu presente. Ludibriados pelo progresso civilizatório trazido pelos brancoseuropeus-portugueses, todos são envolvidos por esta voz atraente e emigram para o outro vilarejo chamado Marandal, em cujas terras as minas de carvão prosperam e representam o símbolo do progresso:

A velha ainda se lembra de que, lá ao longe, a planície se esvai no sopé da serra do Marandal. Vieram os brancos com as suas máquinas para abrirem os grandes buracos na terra e tirar o carvão que os negros carregam para as vagonetas. Mas Alima nunca saiu da planície senão no ano longínquo da grande emigração. Os negros mudaram as palhotas para a nova povoação fundada no Marandal. E tentaram levar a velha. Ela, porém, é já a única pessoa viva que ouviu da boca dos escravos a história recontada do mundo da planície. E recusa-se a abandoná-la... Solitária, a velha Alima tornou-se dona humilde e incontestada da planície que não tem préstimo para mais ninguém...

(MENDES, p.6)

Assim, a terra sobre a qual a ancestralidade vive, personificada pela Velha Alima e pelas vozes dos ancestrais que ali ainda reverberam sobre a terra, fica cercada por um território mal afamado, desiludido, em que seu corpo segue o ritmo lento de abandono de sua história, de sua tradição, junto a narrativa que segue vagarosa.

Com a penetração do colonizador nas terras africanas, muitas são as marcas dolorosas deixadas sobre ela e em seus habitantes, já que nascem num espaço negado, destruído, invadido, sendo obrigados a viver sob um domínio escravocrata numa terra cuja posse lhes foram roubadas. Mas ao mesmo tempo em que o território foi "rasgado" pelos colonizadores, as características dos colonos também foram disseminadas aos colonizadores, portanto, um processo de hibridização foi iniciado, mesmo que indiretamente. A personagem que irá 
conduzir esta marca de vivências num espaço estrangeiro (miscigenado), entre fronteiras e exílios, será o mulato João Xilim, descendente da Velha Alima, mas fruto da cisão entre a ancestralidade com a invasão branca portuguesa, isto é, João Xilim é filho da Negra Kati (que é filha da Velha Alima) com o Patrão Campos (branco português). A sua cor, que é a sua dor, simboliza o cruzamento das duas raças presentes no vilarejo (as terras do Marandal). Por meio deste abraço mal infamado que Xilim veio ao mundo e nele construirá a sua caminhada apoiada nos destinos proporcionados pelas relações sociais que irá desenvolver ao longo do romance.

O exílio e a miscigenação da personagem João Xilim são corroboradas já em sua própria existência e em sua cor de pele, pois não é branco, nem negro, é mulato, filho da dor e do preconceito com a mistura dos traços ancestrais - a cultura nativa, "rústica", junto ao tido branco civilizado - a cultura europeia, "superior e civilizada". Junto a esses fatores, João Xilim nasce numa terra violentada, miserável, enfim, é um ser expatriado e sem lugar, fadado ao fracasso. Como o herói do romance não consegue encontrar um local seguro, no qual possa dar pertencimento a sua vida, decide deixa-lo. Começa então uma longa caminhada clandestina, muitas idas e vindas por uma terra de ninguém. Com isso, João Xilim acaba deixando a sua cultura local para vivenciar em outras. Em sua própria pele já está estigmatizada a mistura das raças, é um ser em cuja estirpe a miscigenação aflora, pois ao entrar em contato com outras culturas e modos de vida, essa hibridização é acentuada e como não consegue equilibrar esta confusão de sentimentos, desloca-se cada vez mais, perde-se em si mesmo, exila-se:

Todos os dias João Xilim vem ver o sol esconder-se no mesmo sítio. E, como o sol, o mulato esconde-se também, mas da gente de sua terra. Leva para ali, para a sua ilhota do silêncio e da solidão, a confusão dos seus sentimentos. No entendimento dos negros da mina do Marandal, João Xilim é o patrício que emigrou e aprendeu a ser diferente deles.

(MENDES, p.10-11) 
Uma grande ferida é implantada na pele e na alma de João Xilim, e esta ferida aberta acompanha o herói durante quase toda a obra, já que está ligada a sua ancestralidade, a sua estirpe. Ao não percebê-la como parte de si, torna-se o seu grande trauma. A memória é intrínseca a Xilim, mas ele não consegue reconhecê-la, então, ao vê-la simplesmente como parte morta em seu antepassado (Vó Alima), decide deixar seu espaço, deixar sua memória, aceita em deixar sua ferida exposta, mas a memória não o deixa, é parte de seu sangue.

João Xilim, portanto, é o fruto da tradição rendida (negra Kati com o Patrão Campos), isto é, a memória que não permaneceu (ancestralidade ligada à Velha Alima) acrescida/injetada pelo "branco civilizador". Deste modo, a ferida de Xilim ficará aberta por toda a sua trajetória, não podendo ser curada, nem por meio de suas atitudes ou mesmo pela própria narrativa, no entanto, há somente uma possível cura para esta dor: trazer seu passado ao seu presente, reencontrá-lo e transformá-lo:

O trauma é a ferida aberta na alma, ou no corpo, por acontecimentos violentos, recalcados ou não, mas que conseguem ser elaborados simbolicamente, em particular sob forma de palavra, pelo sujeito [...] a temática do trauma torna-se predominantemente na reflexão sobre a memória. Ao que parece, as feridas dos sobreviventes continuam abertas, não podem ser curadas nem por encantações nem (GAGNEBIN, p.99) por narrativas...

Assim, a perda da identidade, a dignidade e a justiça social são elevadas ao um grau máximo no momento em que João Xilim deixa a sua terra fisicamente, mas também quando a deixa subjetivamente, surgindo então os exílios geográfico e subjetivo.

O exílio geográfico se dá justamente pelo fato de deixar sua terra natal para viver em outros domínios territoriais, passa seis anos viajando por lugares distantes de seu país. Já o exílio subjetivo é acentuado, tonificado e percebido quando deixa sua terra natal, primeiro fisicamente, para que posteriormente conseguisse perceber que sua dor e seu deslocamento também eram internos, 
não precisava ir muito longe, navegar por terras distantes, para perceber que já era um estrangeiro de seu próprio espaço, de sua própria morada. Ou talvez precisasse, pois a percepção do herói ao retornar das terras distantes lhe dá mais convicção nas suas reflexões e ações sobre seu espaço, mesmo sendo elas desiludidas e sem perspectivas valorosas. Estava confinado sob a sua cor de pele. Ao mesmo tempo em que experimenta a liberdade (deixa sua terra natal para viver longe de sua vergonha) exila-se mais ainda no âmago da sua estigmatizada cor de sua pele. Quanto mais livre, na verdade mais confinado ficava: não é de cá, não é lá, não é dos locais pelos quais passou e pelos quais há de passar. É um ser estrangeiro vivendo seu entre-lugar numa terra desconhecida.

A tensão espacial e subjetiva gerada por Xilim, ao longo de sua trajetória, são intensificadas ao perceber que a sua única ligação com o passado ancestral havia falecido. A velha Alima morre em sua palhota e lá, debaixo do cajueiro, é enterrada. O deslocamento de João Xilim é acentuado assim que descobre este fato, pois após retornar de sua viagem de seis anos por outras terras, a notícia é dada e recebida com a abertura de um remorso muito grande em seu sentimento. Agora, sua avó é somente um símbolo do um passado esquecido nas terras do Ridjalembe. Todos os destinos dos moradores deste vilarejo, que emigraram para as terras do Marandal, foram governados pelos brancos da mina, nenhum deles seguiu a resistência e a convicção da velha Alima. Como Xilim havia saído do Ridjalembe e viajado para as terras distantes, diferenciavase dos demais, ou seja, pelo fato do herói de ter saído de sua terra natal, ao retornar tem a sua percepção distinta dos demais, talvez, se não tivesse saído, seria igual a eles.

Portanto, mesmo com o deslocamento e fuga de seu espaço de origem, um fator positivo é acrescido à personagem, a qual agora, mesmo sofrendo as dores de mulato e de um ser forasteiro de sua própria terra, é uma das esperanças de mudança sob o espaço opressivo e dominado pelos colonizadores. 
A Velha Alima recorda com muita saudade de uma figura muito importante para ela, o seu avô, o seu ancestral direto, o escravo Mafanissane, cuja vida foi marcada pela luta por dias melhores, dias que pudessem ser reconhecidos futuramente pelas próximas gerações por sua nação, mas é justamente aí que a sua grande frustração se instala, seus olhos cansados já não conseguem visualizar chances da posteridade reconhecer este passado que, infelizmente, está ficando cada vez mais e mais soterrado e rarefeito pela ambição do colonizador pelo colono:

Dormita uns instantes sem tempo, para logo acordar sobressaltada. Reconhece o chão pisado por três gerações de negros. Fixa os olhos mortiços nos ramos descarnados do cajueiro plantado por seu avô, o escravo Mafanissane, no dia de sua libertação. Recordando, é depois o mar que the parece, um mar de ondas bravias que foi a fronteira de emigração dos negros para o sul, na grande seca do ano em que lhe nasceu a filha Kati. Kati casou com o capataz dos mineiros do Marandal, depois de ter gerado e parido um filho de branco. Ai começou a solidão enorme da Velha Alima. Solidão a coincidir com a pobreza da planície encurtada de ano para ano ao cansaço dos seus olhos de pálpebras purulentas. Solidão do simbólico cajueiro entre a erva rasteira e os galhos agrestes das micais. E é na planície que fica o mundo moribundo da vida toda da negra Alima.

(MENDES, p. 6)

Mesmo em um ambiente solitário e seco, é ali que Alima se sente pertencida e é neste local que resiste em meio ao espaço ambicioso das terras do Marandal, aonde as minas de carvão prosperavam nas mãos dos colonizadores, enquanto os nativos eram mão-de-obra escrava e barata, por fim, iludidos.

Junto à palhota ressequida da velha Alima, havia um cajueiro que fora plantado por seu avô, o qual tem um valor muito afetivo a ela, pois toda a sua ancestralidade deposita-se nele. O cajueiro (uma planta abundante em Moçambique da qual se extraí a apreciada castanha do caju) é a única vida em meio a tanta miséria, cuja representação é mais do que simplesmente uma abundante árvore na região, ela é a própria simbolização da ancestralidade, com seus galhos ramificando a sua história, mas, assim como ela, é a única espécie que resiste e, ali, irá morrer junto a terra, encerrando, possivelmente, a história de uma geração, deixando suas folhas caírem, seus galhos secarem e 
seus frutos não mais germinarem. Portanto, João Xilim, sendo seu neto, tem uma tarefa árdua, mas muito importante: é filho da miscigenação, a qual tem em sua cor o estigma de mulato, mas ao mesmo tempo, é a representante da hibridação, a mistura e contaminação das culturas, a local com a do colonizador, sendo que esta hibridização incide, também, positivamente sobre a personagem, pois é o ser que desequilibrará seu espaço, entre a resistência da cultura local com a cultura colonial. É o único que sai do vilarejo e vê as terras distantes. Volta diferente, podendo mudar o destino de sua geração, pois tem em suas mãos a experiência da vida interna e externa sobre o vilarejo.

Quase ao fim do primeiro capítulo, a negra Kati, filha da Velha Alima, retorna as terras do Ridjalembe para visitar a mãe e tentar convencê-la a deixar a sua palhota no meio das terras sem vida do Marandal de uma vez por todas. Mas, sem sucesso, não consegue, pelo contrário, este pedido reacende um rancor, uma raiva e uma dor incomensurável na Velha Alima, ao ponto de mostrar a sua própria filha que ali queria morrer, nem que fosse sob os olhos e cuidados de ninguém, já que esta escolha não seria tão diferente da qual já estava vivendo, pois já vivia aos cuidados de si mesma, ela e a sua terra, cuja secura ainda infiltrava a memória de seus avós e, ali, naquela terra batida, onde a saudade dos tempos em que "os negros eram os donos da planície e não tinham outras ambições" que queria ser enterrada, até que os pássaros da sua terra, do Ridjalembe, comessem seus olhos.

João Xilim sabia internamente que enquanto a sua avó estivesse sobre as terras do Ridjalembe, ela era a representante do seu passado, da sua origem, pois tinha para quem a para onde voltar, mas só que desta vez, ao retornar para as terras dos seus ancestrais, tudo isso já tinha ido, o espaço da memória teria sido apagado, ou melhor, a sua maior representante se juntou ao cajueiro e está agora junto ao seu avô Mafanissane, completando a ascendência entre os galhos ressequidos do cajueiro que agora dependem de João Xilim para serem levados adiante ou serem extintos de vez, nesta terra em que se nasce estrangeiro da própria pátria: 
Katiesperava, escondida, que a mãe acabasse $e$ as aves the comessem os olhos, conforme sua determinação. E depois supultara-a debaixo da copa do cajueiro ressequido. E João Xilim sente remorsos de não ter feito mais companhia à avó que para ele agora representa um simbolo. Os outros ficaram sempre no Marandal, esquecidos do passado do Ridjalembe, deixando governar seus destinos pelo branco da mina.

(MENDES, p.11)

Com a morte da velha Alima, o mulato clandestino terá pela frente um grande desafio: lutar pela (re)construção de seu lugar e pelo (re)conhecimento de sua terra, unindo a sua experiência externa e interna que teve de seu país. Agora não tem para quem mais voltar, terá que criar novos laços por meio de suas novas relações sociais, ou mesmo reatar laços deixados no passado, para que assim busque a reconstituição de sua identidade fragmentada por tantas idas e vindas que o deslocaram geograficamente e, principalmente, afetivamente/subjetivamente. Sem a referência do passado, Xilim terá que balancear a experiência de sua caminhada entre fronteiras, isto é, sendo um ser nascido num espaço estrangeiro numa cor repelida por todos, terá que lançar mão desses "atributos" a seu favor, (re)construindo sua trajetória e provando que sua cor é sua dor, mas, também, poderá ser sua salvação.

\section{Referências bibliográficas}

CANDIDO, Antonio. Formação da literatura brasileira. Belo Horizonte: Itatiaia, 1997.

COUTO, Mia. Que África escreve o escritor africano? In: Pensamentos, Caminhos. Cape townCape, 2002. Disponível em:http://www.esquerda.net/media/soc_lit_africana.pdf. Acesso em: 13 mai., 2012.

EAGLETON, Terry. Ideia de cultura. Tradução Sandra Castello Branco; revisão técnica Cezar Mortari. São Paulo: Editora UNESP. 2005.

FRANTZ, Fanon. Os condenados da terra. Trad. José Laurênio de Melo.Rio de Janeiro: Civilização Brasileira, 1979. 
GAGNEBIN, Jeanne Marie.Lembrar escrever esquecer. São Paulo: Ed. 34, 2006.

HAMILTON, Russel G. Literatura Africana, literatura necessária.Tradução Russel Hamilton. Lisboa: Edições 70, 1984.

HOMI, Bhabha. Nation and narration.London and New York: Routledge, 1990.

MENDES, Orlando. Portagem. São Paulo: Ática, 1981.

SANTILLI, Maria Aparecida. Estórias africanas: história e antologia. São Paulo: Ática, 1985.

SAID, Edward. Cultura e imperialismo. Trad. Denise Bottman. São Paulo: Companhia das Letras, 1996.

SILVIANO, Santiago. Uma literatura nos trópicos: ensaios sobre dependência cultural. 2.ed. Rio de Janeiro: Rocco, 2000. 